\title{
Knowledge and Attitude on Insulin Self Administration Among Type One Diabetic Patients in Mekele Hospital,Tigray, Ethiopia, 2015
}

\author{
Hadgu Gerensea ${ }^{1, *}$, Admasu Moges ${ }^{2}$, Birikity Shumiyee ${ }^{2}$, Frweyine Abrha ${ }^{2}$, Medina Yesuf ${ }^{2}$, \\ Tewelde Birihan², Tsiyon Birhanu", Zomanesh Getahun ${ }^{2}$
}

${ }^{1}$ School of Nursing, Axum University, Axum, Ethiopia

${ }^{2}$ Axum University, Referral Hospital, Axum, Ethiopia

\section{Email address:}

hadgugerensea2015@gmail.com (H. Gerensea)

\section{To cite this article:}

Hadgu Gerensea, Admasu Moges, Birikity Shumiyee, Frweyine Abrha, Medina Yesuf, Tewelde Birihan, Tsiyon Birhanu, Zomanesh Getahun. Knowledge and Attitude on Insulin Self Administration Among Type One Diabetic Patients in Mekele Hospital,Tigray, Ethiopia, 2015.

Advances in Surgical Sciences. Vol. 3, No. 5, 2015, pp. 32-36. doi: 10.11648/j.ass.20150305.11

\begin{abstract}
Introduction. insulin is a valuable drug for, those who are in need of it. Insulin will have tremendous impact, when used properly. Intensive insulin therapy was essential in the maintennce of strict glycemic control among insulin requiring patients with diabetes. However this presents challenges in the face of the complexities associated with insulin use and also taking in the consideration the potential danger associated with inappropriate use. Insufficient knowledge and attitude of insulin self administration can result in preventable complication, adverse patient outcome, poor adherence to therapy and invariably poor glycemic control. Objectives. to assess knowledge and attitude on insulin self administration among type 1 DM patients in Mekele hospital 2015. Methodology. Institution based descriptive cross sectional study was conducted. The study subject where type 1 DM patients in Mekele hospital (attending chronic follow up).Data was collected by interview using pre tested structured questionnaires. The data was entered and analyzed using SPSS version 16. All type one DM patients were included in the study. Result. among 141 respondents, more than half 78 (55.3\%) of them had average knowledge and majority $96(68.0 \%)$ of the participants had favorable attitude. Conclusion and recommendation. the finding of this showed that type 1 diabetic patient had average knowledge and favorable attitude towards self administration of insulin injection. It is suggested that more should be done on areas like medias, health professionals on health education towards insulin self administration for type 1 DM patients.
\end{abstract}

Keywords: Knowledge, Attitude, Insulin Self Administration

\section{Introduction}

Diabetes is a public health problem which is a chronic disease and is now as an epidemic in both developed and developing counties. DM is recognize $\mathrm{d}$ as one of the leading cause of death and disability worldwide The physical social and economic factors involved in the management of diabetes are a continuous strain for health sector as well as to government agencies While there has been a great improvement in the knowledge, epidemiology and management of this condition in the developed world, there has been little or no improvement in sub - Saharan Africa including Ethiopia.[1]

Insulin is one of the harm full medications if used inappropriately. For this reason, it is identified as one of the five "high alert" medications that have the greatest risk of causing injury to Patients because of medication errors. [2,3]

Intensive insulin therapy is essential in maintenance of strict glycemic control among insulin requiring patients with diabetes. However this presents a challenge In the face of the complexities associated with insulin use and also taking in to consideration the potential dangers associated with inappropriate use. Insufficient knowledge of insulin self injection can result in preventable complication, adverse patient out came full adherence to therapy and invariably poor glycemic control [4]. Many insulin 
requiring diabetes patient possess poor knowledge of insulin use are conversant with some important terms such as keto - acidosis, insulin reaction hypoglycemia. [5]

It is a growing concern worldwide; while there has been a great improvement, in the knowledge, epidemiology and management of this condition in the developed worlds, there has been little or no improvement in sub Sara Africa including Ethiopia [1]

Knowledge about insulin self administration is a fully requests for individuals and communities to take action for control of diabetes the treatment for type 1 diabetes (IDDM) is inject able insulin therapy which requires coordination and understanding of both the individuals with diabetes and those responsible for diabetic care. The diabetes patients who are on insulin need to be knowledgeable regarding the disease and insulin therapy and also they must have a competency and positive attitude towards self administration of insulin injection to overcome the barriers of insulin injection and to have good glycemic control. Patients need knowledge to improve the competency level of self administration of insulin which in turn will help in better glycemic control and avoid complications. Glycemic control and prevention of complication will reduce the cost of treatment and diabetes related mortality [6]

The long term prognosis of type 1DM is said to improve with a complex demanding and often intensive regimen and maintenance of lower blood glucose level is said to reduce the risk of long term complication by as much as $60 \%$ [7].

Many studies conducted elsewhere in the world on insulin therapy have showed that the knowledge and awareness about the disease can have positive influence on knowledge and attitude of patients regarding Insulin Self administered that could lead to better management of diabetes and eventually good quality of life. However, knowledge and attitude gap exists in type 1 diabetes mellitus management that does not allow patients and healthcare professionals to implement life style changes could reduce the morbidity and mortality associated with diabetes.

Diabetes is one of the major causes of premature illness and death worldwide. More than $80 \%$ of diabetes death occurs in low and middle - income countries. In our study area, Mekele hospital health professionals alone can't provide high quality care.

Diabetes being a chronic illness requires sound knowledge and attitude of self insulin administration by patients, so that they can contribute meaningfully in the management of their lives. However there was no enough study conducted on knowledge and attitude of insulin self administration among type 1 DM patients.

The study has been conducted to assess the knowledge and attitude of insulin self administration with type 1 DM patients in Mekele hospitals. The findings of this study will help in identifying population knowledge gap and their attitude towards insulin self administration which might help in designing effective educational program for safe insulin self administration and also will be used as a base line in the future for further study.

\section{Objectives}

\subsection{General Objectives}

- To assess knowledge and attitude on insulin self administration among type one diabetic patients in Mekele hospital, Tigray, Ethiopia 2015

\subsection{Specific Objectives}

- To determine knowledge on insulin self administration among type 1 diabetic patients.

- To explore attitude of type 1 diabetic patients on insulin self administration

\section{Methodology}

\subsection{Study Area}

The study was conducted in Mekele hospital, which is a teaching and regional hospital located in Mekele town, North Ethiopia, at $783 \mathrm{~km}$ away from Addis Ababa, the capital city of Ethiopia. Mekele is one of the biggest cities in Tigray national regional state with a population more than 150341. It is a member of governmental health institution;

\subsection{Study Design and Period}

Institution based cross sectional study design was used to assess knowledge and attitude on self - administration of insulin from January to August 4, 2015.

\subsection{Population}

\subsubsection{Source Population}

The source populations for this study were all type 1 diabetic patients who have follow up in Mekele hospital.

\subsubsection{Study Population}

The study populations for this study were all type 1 diabetes patients who came to Mekele hospital for follow up during the study period.

\subsection{Inclusion and Exclusion Criteria}

\subsubsection{Inclusion Criteria}

All type 1 diabetic patient attending at Mekele hospital chronic follow up clinic were included in this study

\subsubsection{Exclusion Criteria}

Type 1 diabetes patients who were severely ill, age less than 18 year and psychiatric patients were excluded from the study.

\subsubsection{Sampling Size Determination}

All type one DM who has follows up on Mekele hospital was included in the study. A total of 141 were taken from 155 types one DM with $90 \%$ response rate. 


\subsection{Study Variable}

\subsubsection{Dependant Variable}

- Knowledge of insulin self administration

- Attitude of insulin self administration

\subsubsection{Independent Variable}

Age, Sex, Marital status, Education, Religion, Health profile related variables, Duration of treatment, DM association member ship and family history of diabetics were independent variables.

\subsubsection{Data Collection Method}

Interview with structured closed ended questionnaire was performed by revising questionnaires developed from similar study, which was conducted in Mangalore and adapted to the objectives of the present study to collect quantitative data. The questionnaire was designed in English and translated to Tigrigna (local language) for better understanding of the study participants and again translated back to English by other person to check validity.

\subsubsection{Data Quality Assurance}

The prepared questionnaire was pre - tested on 15 type 1 DM patients in shire, suhul hospital, then some modification were made before applied on the study subject

Data Processing and Analysis

Data processing, analysis and interpretation have been done using SPSS. The frequency and percentage of all variables was determined.

\subsubsection{Operational Definition}

Good knowledge - a subject who answered 9 - 13 (above $66 \%$ ) correct responses from knowledge questions

Average knowledge - a subject who answered 5 - 8 (33.3 $66.6 \%$ ) response from knowledge question

Poor knowledge - a study participant who answered 0 - 4 (below 33.3\%) corrects response from knowledge question

Attitude - these are feelings and beliefs expressed by patients towards self administration and are evident from score obtained by their response in validated rating scale. according to their attitude response the study participants were categorized as 6 and above $(>49 \%)$ favorable attitude and below $6(50 \%)$ unfavorable attitude.

Insulin self administration -the injection of insulin expected to be administered at home without assistance. This includes preparation of article, with drawl of injection, and administration after care.

\subsubsection{Ethical Consideration}

Ethical clearance was obtained from Aksum University College of health sciences department of nursing and permission obtained from Mekele hospital administrative office. Informed verbal consent was obtained from each study subjects after explanations of the importance of the study. They had all the right not to be involved in the study or not to answer any question. We were also informed that all of their response was confidential.

\section{Result}

\subsection{Socio Demographic Characteristics of Study Subjects}

Total of 141 study participants were interviewed using structured questionnaires giving response rate of $90 \%$

From the total sample size population, almost half 68 (48.1\%) of the respondents were between the age group of 18 - 31 years followed by 31 - 40 years and 41 - 50years which were $34(24.11 \%)$ and $22(15.6 \%)$ respectively. More than half $72(51 \%)$ of them were male. The majority $99(70.2 \%)$ of the participants were orthodox followers. sixty four $(45.3 \%)$ Subjects were married and only $8(5.6 \%)$ were widowed. Regarding the educational status of study subjects, majority of them $67(47.5 \%)$ was primary school. (Table 1$)$

Table 1. Socio demographic characteristics of type one DM in Mekele hospital, 2015.

\begin{tabular}{lll}
\hline Variables & & Frequency (\%) \\
\hline \multirow{4}{*}{ Age in year } & $18-30$ & $68(48.1)$ \\
& $31-40$ & $34(24.11)$ \\
Sex & $41-50$ & $24(15.5)$ \\
& $51-60$ & $12(8.5)$ \\
Religion & $>60$ & $5(3.5)$ \\
& Male & $72(51)$ \\
& Female & $69(49)$ \\
& Orthodox & $99(70.2)$ \\
Marital Status & Muslim & $30(21.27)$ \\
& Protestant & $12(8.5)$ \\
& Other & - \\
& Married & $64(45.39)$ \\
& Single & $52.6(37.58)$ \\
Educational Status & Divorced & $17(12)$ \\
& Widowed & $7(4.9)$ \\
& Illiterate & $15(10.6)$ \\
& Primary school & $67(47.5)$ \\
& Secondary school & $46(32.6)$ \\
\hline
\end{tabular}

\subsection{Health Profile of Study Subjects}

Majority $104(73.8 \%)$ of the study participant had no family history of diabetes. Most of 121 (85.8\%) participants were not a member of diabetic association. Concerning duration of drug treatment, $49(34.7 \%)$ of study participants were less than one year and $30(21.2 \%)$ were between $3-5$ years duration.

Table 2. Health profile of type one DM in Mekele Hospital, 2015.

\begin{tabular}{lll}
\hline Variables & & Frequency (\%) \\
\hline \multirow{2}{*}{ Family history DM } & Yes & $35(24.5)$ \\
& No & $104(73.5)$ \\
DM association membership & Yes & $20(14.2)$ \\
& No & $121(85.8)$ \\
& $<1 \mathrm{yr}$ & $47(32.9)$ \\
Duration of insulin therapy & $1-3 \mathrm{yr}$ & $33(23.4)$ \\
& $3-5 \mathrm{yr}$ & $30(21.2)$ \\
& $>5 \mathrm{yr}$ & $31(22.3)$ \\
\hline
\end{tabular}

\subsection{Knowledge Regarding Insulin Self Administration}

More than half $89(63 \%)$ of the study subjects knew the definition of diabetes is high blood glucose and majority of 
the participants knew about insulin. Nearly two third 97 $(68.8 \%)$ of study subject knew insulin vial is stored in refrigerator or cold place. Greater than half 75 (53.1\%) of respondents got the information about insulin from health workers and only $5(3.1 \%)$ got from mass media.

The majority $117(83 \%)$ of the study participant just had taken insulin soon after or just before taking food. Nearly three fourth $(72.5 \%)$ of the study subjects knew the advantage of site rotation. $55(39 \%)$ Of respondent knew more than three sites for insulin injection.

Only $23(16.3 \%)$ of respondent knew the angle of insulin injection is $45^{\circ}$. Majority $97(68.9 \%)$ of participant didn't knew the distance to rotate insulin injection on the same site is one thumb.

$30(21.2 \%)$ Study subjects understood the ways to reduce pain during insulin injection. 55 (39\%) respondents answered the correct responses on the reason of massaging the site after injection.

Only 15 (10.6\%) Study participants had knowledge on the complication of insulin therapy and nearly three fourth 108 $(76.5 \%)$ knew the benefit of insulin self administration.

Table 3. Data on knowledge regarding general information on DM and insulin self administration

\begin{tabular}{|c|c|c|}
\hline \multirow{2}{*}{ Item } & \multirow{2}{*}{$\begin{array}{l}\text { Correct answer } \\
\text { Frequency }(\%)\end{array}$} & \multirow{2}{*}{$\begin{array}{l}\text { Wrong answer } \\
\text { Frequency (\%) }\end{array}$} \\
\hline & & \\
\hline Know about diabetes mellitus & $120(85.1)$ & $21(14.91)$ \\
\hline DM means high blood sugar & $89(63.1)$ & $52(36.87)$ \\
\hline Know about insulin & $118(83.6)$ & $23(17.8)$ \\
\hline Insulin vial is stored in the refrigerator or Cold place & $98(68.7)$ & $43(31.2)$ \\
\hline Insulin injection is taken soon after Or just before taking food & $117(82.9)$ & $24(17)$ \\
\hline The sites for insulin injection are abdomen, Thigh, Glutei and deltoid & $56(39)$ & $85(60.9)$ \\
\hline The distance to rotate on the same site is One thumb & $44(31.2)$ & $97(68.7)$ \\
\hline $\begin{array}{l}\text { Ways to reduce pain during insulin injection are Inters the skin, do not manipulate the needle once Inserted, } \\
\text { avoiding re using of the same site }\end{array}$ & $30(21)$ & $110(78.8)$ \\
\hline $\begin{array}{l}\text { The complications of insulin therapy are low Blood Sugar, insulin allergy, insulin resistance and wasting of } \\
\text { subcutaneous tissue and wasting of subcutaneous tissue }\end{array}$ & $15(10.6)$ & $126(89.3)$ \\
\hline The use of rotation of the injection site is to Reduce pain, prevent wasting of sub - cutaneous Tissues & $98(69.5)$ & $43(30.4)$ \\
\hline Massage after injection is used to Reduce the rapid absorption of insulin & $75(76.5)$ & $33(23.4)$ \\
\hline
\end{tabular}

The mean knowledge score of study subjects was 7.07 with a maximum possible score of 13 . Only $18(13.07 \%)$ of participants had good knowledge, $78(55 \%)$ participants had average knowledge and $45(31.8 \%)$ had poor knowledge regarding diabetes and insulin self administration.

\subsection{Attitude Regarding Insulin Self Administration}

$31(22 \%)$ Study participants were agreeing with insulin causes other health problems and $86(60.7 \%)$ study subjects believed insulin is not the cause for other health problems. Majority $66(46.9 \%)$ study subjects thought insulin self administration correctly decrease glucose in the blood only $22(15.9 \%)$ of respondents disagree with insulin self administration correctly decrease glucose in the blood.

Greater than half $91(64.6 \%)$ of study subjects believed that insulin self administration is not tiresome and half 71 (50.3\%) of respondent thought insulin self administration brought stigma.

Table 4. Data on Attitude of type 1 diabetic patients regarding on insulin self administration.

\begin{tabular}{|c|c|c|c|}
\hline \multirow{2}{*}{ ITEM } & AGREE & NOT SURE & DISAGREE \\
\hline & Frequency (\%) & Frequency (\%) & Frequency (\%) \\
\hline Insulin cause other health problem & $31(22)$ & $25(17.7)$ & $85(60.2)$ \\
\hline Insulin self - administration correctly Decrease glucose in the blood & $66(46.8)$ & $52(36.8)$ & $23(15.6)$ \\
\hline Insulin self administration is a tiresome & $44(32.1)$ & $14(9.9)$ & $91(64.5)$ \\
\hline Insulin self administration bring stigma & $71(50.3)$ & $16(11.3)$ & $54(38.2)$ \\
\hline Insulin self administration is beneficiary & $99(70.2)$ & $30(21.2)$ & $12(8.5)$ \\
\hline
\end{tabular}

Out of 141 type 1 diabetic patients included in this study, $95(67.4 \%)$ had favorable attitude and 46 (32.5\%) had un favorable attitude. The mean attitude score of the participants was 3.07 with maximum score of 15 . This result showed that most type 1 participant had favorable attitude on insulin self administration.

\section{Discussion}

The study was carried out to assess the knowledge and attitude of type 1 diabetic patients on insulin self administration in Mekele hospital. The study showed that the mean knowledge score of study subjects were 7.27. Study participants had average knowledge regarding insulin self administration. This study had demonstrated average level of knowledge regarding insulin self administration. The prevalence of knowledge was lower compared to studies done in India and Bangalore which were $68 \%$ and $86.7 \%$ [6, 8].This difference from the previous studies might be due to high illiteracy rate of study participants, lack of self insulin injection education facilities and low access of media and NGOs in awareness creation about insulin self administration.. 
Of the study participants thought that diabetes mellitus mean high blood sugar. This was better than a similar study done in Bahir Dar, Fellegehiwot hospital which was 33.4\% [9]. This difference may be related with patient health profile difference

Majority of type 1 diabetic patients (82\%) awarded that the action of insulin is to lower glucose in the blood. This study was supported by similar study conducted in Bangalore $(80 \%)$ [8].

Another important finding of this study was a limited knowledge about the complication of insulin therapy (10\%), which was much lower compared to studies done in Bangalore (86.67\%) and Nigeria $(66.4 \%)$ [8,10]. this difference might be due to high illiteracy rate, environmental factor and socio economic status of the study participant of the present study. This level of inadequate knowledge regarding complication of insulin therapy may lead to decrease awareness of patients for complication and these are high economic burden of the country in the management of complications which comes due to inadequate awareness of the complications and lack of adequate organized heath education about diabetes.

Participant aware the sites of insulin injection are abdomen, thigh, glutei and deltoid. This finding was different from a study conducted in Bangalore, which was 53.3\%. [8] This could be lack of organized health education and negligence of health care workers on insulin self administration. Inadequate knowledge regarding site of insulin injection may lead to develop complication of insulin therapy. These findings high light the need of emphasizing insulin injection during diabetes education.

Among respondent, 68.6\% knew an open vial could be preserved in refrigerator or cold place. This study had slight different from study conducted in Indian and Bangalore $72.4 \%$ and $78.33 \%$ respectively. $[6,8]$ This difference from the previous studies could be low economics status of study subjects and health patient negligence to educate about insulin vial preservation.

The mean attitude score of the study subjects was. Participants had favorable attitude and study participants had favorable attitude and study participants had unfavorable attitude. It was lower compared to study done in Bangalore, which was $81.7 \%$ had favorable attitude. $18.3 \%$ had most favorable attitude and none of them had unfavorable attitude. [8] The difference from Bangalore finding might be lack of trained man power to create adequate awareness toward insulin therapy. The present finding was better than another study conducted in India which was only $32 \%$ had favorable attitude and others had unfavorable attitude towards insulin self administration. [6] This difference might be due to environmental and socio - cultural factors of participants

Limitation of the study

This study was also limited to diabetic patients who were on subcutaneous insulin therapy and only site was included in Mekele hospital (chronic follow up).it assessed only their knowledge and attitude practice was not included. We did not observe what actually do while they insert insulin

\section{Conclusion}

The finding of this study showed that type 1 diabetes patients had average knowledge and less favorable attitude among type 1 diabetes toward insulin self administration but there is still there is a gap on knowledge and attitude of type 1 diabetes patients on insulin therapy.

\section{Recommendation}

To Medias; most of the patients get the information from health workers, there is still knowledge gap so that it is better to deliver updated information from the media.

To health science professionals: at the time of follow up strict education has to give for each patient in order to increase their knowledge, attitude and practice.

\section{References}

[1] Edna S. Majaliwa, B. E. Jerome Elusiyan. Omotayo O et al. type 1 diabetes mellitus in the African population; Epidemiology and managemet of challenges, Acta Biomed; 2008.

[2] Derr RL, Sivanandy MS, Bronchi - hall L, Rodrigeuz A. insulin related knowledge among health care professional in internal medicine. Diabetes spectr 2007; 20; $177-185$.

[3] The Joint commission on accreditation of health care organization (JCAHO) JCAHO suggests ways to prevent medical errors. Health risk man, 22. 19 - 20.

[4] Gark MK. Current perspective in insulin therapy in the management of Diabetes mellitus. J Indian Med Assoc 2002 Mar; 100 (3); 194 - 5; 2012.

[5] Majra. J P. Acharya D. Awareness regarding self care among dianetes in Rural India, Middle East journal of family medicine. July 2009.7 (6); 25 - 26.

[6] Surendranath; A, Nagaraju B, Padmavathi GV, et a. A Study to assess the knowledge and attitude of insulin self administration among patuents with diabetes mellitus in India. Asian journal of pharmaceutical and clinical research vol 5, issue $1,2012$.

[7] DCCt Research group. effect of intensive diabetes treatment on the development and orogression of long term complication in adolescent with insulin dependent diabetes mellitus, J 1994; 125 (2) - 177.

[8] Namita S. A descriptive study to assess the $g \mid$ knowledge and attitude regarding self administration of insulin injection among DM patients in kempa chaluvamba general hospital at Malleswaram, Bangalore. Nov 2005.

[9] Sr. Tresa P. Effectiveness of individual planned teaching on self insulin Administration for patients with diabetes mellitus in A selected hospital at mangalore. Rajiv Gandhi University of health sciences, Karnataka. 25 - $05-2005$.

[10] Jasper U. Opara M, Pyiki E, Akinrolie O. knowledge of insulin use and its determination among Nigerian insulin requiring diabetes patients. journal of diabetes and metabolic disorder 2014, 13; 10. 